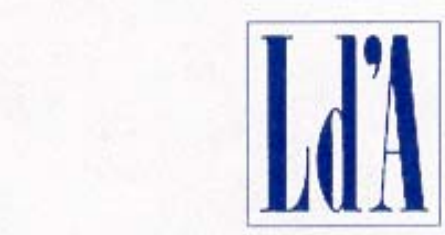

CENTRO STUDI LUCA D'AGLIANO

WWW.DAGLIANO.UNIMI.IT

CENTRO STUDI LUCA D’AGLIANO

DEVELOPMENT STUDIES WORKING PAPERS

N. 232

May 2007

\title{
Relying on the Information of Others: Debt Rescheduling with Multiple Lenders
}

\author{
Claude Fluet* \\ Paolo G. Garella**
}

* Université du Quebec à Montréal and CIRPEE

** University of Milan and Centro Studi Luca d'Agliano 


\title{
Relying on the Information of Others: Debt Rescheduling with Multiple Lenders
}

\author{
Claude Fluet and Paolo G. Garella* \\ This version: 7 November 2007
}

\begin{abstract}
Can inertia in terminating unsuccessful loans (creditor passivity) be due to the multiplicity of lenders in loan arrangements? Can a lender reschedule, betting against his odds? Private information in the form of bad but coarse news, that would prompt foreclosure on its own, will instead lead to rescheduling. The gamble is that other lenders may have sharper information. At equilibrium, rescheduling occurs even if all lenders received bad news. This is inefficient (increasing the cost of capital) compared to perfect information sharing. However, barren information sharing, at equilibrium there is no excess reliance on the information of others from a social point of view. The paper also contains an extension dealing with "financial scandals".

Keywords: Debt contracts, asymmetric information, rescheduling, insolvency, Bayesian games. JEL: G32, G33 D82, D86.
\end{abstract}

*Fluet: Université du Québec à Montréal and CIRPEE (fluet.claude-denys@uqam.ca). Garella: Department of Economics-University of Milano (paolo.garella@unimi.it). We gratefully acknowledge financing from FQRSC, SSHRC, the University of Crete Marie Curie TKF (E.U. 6th Progr., MTKD-CT-014288) and the Italian Ministry of Education (Cofin 2003). We thank, for helpful comments, Pierpaolo Battigalli, Patrick Bolton, Giacomo Calzolari, Daniela Fabbri, Marie-Cécile Fagart, Françoise Forges, Mario Gilli, Erwan Morellec, Marco Ottaviani, Lambros Pechlivanos, Nikos Vettas, and seminar participants at IBF-HEC Lausanne, Athens University of Business and Economics, Università MilanoBicocca, Università Statale di Milano, Università Bocconi-Milano, Università di Bologna, ASSET-2006 annual meeting in Lisbon, IGIER-CSEF 2007 Symposium on Economics and Institutions. Remaining errors and omissions are our own. 


\section{Introduction}

Large defaults and bankruptcies, whether by firms or sovereign debtors, attract the attention of both media and experts, with the first often wondering why the debtor was allowed to accumulate such huge liabilities. After any default event, hindsight trivially reveals that "too much" money was invested or that the debtor was stopped "too late". Notwithstanding the obvious problem of perspective, non-experts often reproach banks of excessive passivity towards borrowers. The suggestion is that they did not wish to act accordingly to what they knew. ${ }^{1}$

The question here raised is different from why lenders may fail either to gather sufficient information initially or to exert efficient monitoring of a debtor's behavior later on. The question is why a lender with bad news about an ongoing loan may decide to ignore what he knows, inefficiently delaying the liquidation of bad projects. The problem we address is not, therefore, whether lenders acquire sufficient information but whether they efficiently use information already in their possession.

Available information is often hard to read, especially in the case of large debtors. It is also incomplete, so that assessing solvability may be difficult even for well trained professionals. Moreover, analysts may not be always make it plain to investors what they really think. ${ }^{2}$ Therefore, allowing for the fact that lenders often have a foggy idea of a debtor's solvability, the question is then what to do when the debtor runs into problems. We ask whether,

\footnotetext{
${ }^{1}$ Regarding excessive lending in the case of sovereigns, see Paul Blustein's (2005) account of investors' (and the IMF's) attitude towards Argentina between 1995 and the full eruption of the debt crisis in 2001. Blustein suggests that investors do not seem to have drawn the logical consequences from warnings. As reported by the Argentine press at the time, Teresa Ter-Minassian, an IMF economist in charge of a report on Argentina, warned publicly in April 1998 that the Argentine economy contained a "Molotov cocktail". Blustein writes (p. 200): "Some market participants blame the IMF for fueling their optimism, but in one instance when the Fed blew the whistle loudly and publicly-the Ter-Minassian visit of April 1998 when her "Molotov cocktail" comment and other warnings were circulated - the markets paid little heed". Though our story is more specific to corporate debt and to an environment without political implications, this episode shows that decisions to ignore bad news do play a role at times.

${ }^{2} \mathrm{~A}$ report on self-censorship for the case of the Argentine bond market is found in Chapter 4 of Blustein (2005).
} 
loosely speaking, it is then not unreasonable for a lender with a foggy view of the borrower's current profile to "think twice" before going for liquidation. In particular, to "wait and see" can be attractive if the loan arrangement involves multiple lenders. Every single lender is aware that other lenders also receive information about the borrower. It is then tempting to gamble that other lenders may have obtained more precise information and may therefore be in a better position to decide. Can this be rational? And what if all lenders decide to reschedule their loans? Is there too much relying on the possibility of others being better informed? Does this imply that there is excessive rescheduling at equilibrium?

We provide here an explanation for lender passivity, based on (i) the presence of multiple lenders in the loan arrangement, (ii) the information asymmetry between lenders. The first point draws on the observation that large loans usually involve many lenders. The second introduces a so far neglected form of asymmetry: the asymmetry in information precision. This will prove to be a key element of our story.

To characterize the game played in a multiple-lender loan, consider that, when a borrower gets in trouble, a lender who does not renew his loan is likely to trigger liquidation. Liquidation has two crucial attributes in our story: "irreversibility" and "strong complementarity". By irreversibility we mean that, once a project is liquidated or a borrower led to bankruptcy, additional financing can usually not be obtained. The value to be shared among the parties is accordingly fixed, i.e., independent of the actions they may subsequently take. ${ }^{3}$ By "strong complementarity" we mean that if one lender goes for it, liquidation determines the payoffs of all lenders, rendering each lender pivotal in the liquidation but not in the rescheduling decision. That some lenders are not always pivotal is discussed in Section 4 and in the Conclusion.

The inefficiencies arising in the presence of multiple lenders are well

\footnotetext{
${ }^{3}$ Of course this simplification cuts away a branch of the game tree describing the liquidation process. This way to proceed is common in the literature. An exception is Guiso and Minetti (2006). Kahl (2002) analyzes liquidation as a two step procedure, where refraining from liquidating at an early stage is a way to allow for more information to be gathered in order to take a more informed decision later on. The advantage of waiting comes there at the cost of delaying the restructuring of solvent but illiquid firms.
} 
known. The literature has attempted to explain why multiple lending arrangements occur (for an empirical assesment of the phenomenon see Ongena and Smith 2000 and Detragiache et al. 2000) in spite of these inefficiencies. Papers in this vein include Bolton and Scharfstein (1996), Rajan (1992), Petersen and Rajan (1994), Detragiache et al. (2000) and, more related to the present framework, Dewatripont and Maskin (1995). The presence of multiple lenders in recontracting of loan arrangements may lead to a lack of coordination, or to free riding, that prevents socially optimal debt restructuring (Detragiache, 1994, Hart and Moore, 1995, Bolton and Scharfstein, 1996, Detragiache and Garella, 1996). However, making renegotiation difficult may also act as a device to correct for borrowers' incentives to use funds to undertake socially inefficient projects (Hart and Moore, 1995).

Having more than one lender is often argued to dilute the incentives to monitor the borrower, counterbalancing the discipline effect. This too may not always decrease efficiency: Dewatripont and Maskin (1995) develop a setup where (i) initial debt is signed with one lender only, (ii) due to limited fund availability, refinancing involves a second lender. They show that the incentives to monitor by the first lender are reduced by the need to involve a second lender, who will appropriate part of the generated gains. As a result, less monitoring may bring forth less refinancing at the intermediate stage, inducing a virtuous self-selection of borrowers at the initial date, favoring more efficient assignment of funds; they show that this correction would disappear if credit were to be provided by a centralized agency.

Guiso and Minetti (2004) study a setup that shares some assumptions with the present paper: multiple lenders arrangements involve banks that are either relationship banks or transaction banks, where relationship banks have better information about the borrower than transaction banks do. Furthermore, they assume that relationship banks, thanks to their superior information, can selectively choose which assets to repossess in a liquidation. ${ }^{4}$ Our paper shares with Guiso and Minetti (2004) the idea that lenders receive private information that can differ in precision.

We analyze a simple recontracting game involving one (large) borrower

\footnotetext{
${ }^{4}$ Related to this issue, Berger, Klapper and Udell (2001) empirically test various hypotheses about the role of relationship vs. arms-length loans in Argentina.
} 
and two creditors. The project financed at date 0 has one period duration. At the end of the period, with probability less than one, the project is successful and delivers a given return. Otherwise, the project does not deliver any cash flow at date 1 . In this state, if allowed to continue one additional period, the project will yield a stochastic final payoff. Each lender observes an exogenous private signal about the value of the loan returns at date 2. Conditional on this information, each lender independently decides wether to reschedule his loan or to foreclose. The signals received can be of two types: precise or coarse. Information received at the rescheduling stage could in principle be merged. However, as we shall show, a communication game will in general fail to provide equilibria where truthful revelation of information occurs, so that information is not merged. Accordingly, decisions wether to reschedule must be taken based only upon the privately received signals. ${ }^{5}$

Strikingly, if a bank receives unfavorable but coarse information, a condition that would induce a refusal to refinance if the bank were the sole lender, it will not do so at equilibrium when another lender is involved. Indeed, when the likelihood that the other lender is well informed is sufficiently large, rescheduling by a coarsely informed bank is a dominant strategy. The upshot is that when both banks receive the coarse signal, they both decide to ignore it and reschedule instead of liquidating. In other words, both banks behave as if they had received favorable information. Such behavior, that external observers would presumably describe as "unwise", arises out of equilibrium strategies enacted by rational players. Obviously, the use of information is then not socially optimal compared to a situation where information is merged. Nevertheless, we show that subject to the same information structure the equilibrium could not be improved upon by a social planner dictating the banks' actions. In this sense, given the informational

\footnotetext{
${ }^{5}$ Other reasons may prevent information to be merged. Padilla and Pagano (2000) find that partial information sharing may result in a game where banks choose the amount of information to be shared as a pre-commitment device. The type of information that is shared in reality is described in Jappelli and Pagano (1993) and refers only to past defaults, credit history and debt exposures. Guiso and Minetti (2004) argue that the borrower can selectively control the information flows. We can also think of cases where lenders have private interests with large firms, for instance when they also finance suppliers of these firms, or when they can buy or sell outstanding bonds issued by the borrower. Rajan (1994) expands on bank's ability to manipulate information about borrowers.
} 
constraints, there is no excessive rescheduling at equilibrium. ${ }^{6}$

Lenders in our game have interests that are not fully conflicting: if some good information is around, every lender is better off by rescheduling rather than liquidating. Key to the decision to reschedule by an ill informed lender is therefore the "strong complementarity" of liquidation: if the other bank is well informed, it will trigger liquidation when it is optimal to do so. Of course, and paradoxically, when both lenders are ill informed they both rely on this possibility and inefficient rescheduling occurs.

We also devote a brief section to analyze some implications of our "creditor passivity" explanation for the case where some lenders can never be well informed while other lenders, possibly biased by private benefits, may or may not be informed. An apparent conflict then arises between lenders; this section can be read as an application of our theory to "financial scandals".

In an appendix, we discuss the case where the two banks are treated asymmetrically under liquidation, in the sense that if one triggers liquidation while the other reschedules, the first gets a higher payoff than the second. A lender receiving the precise signal will then liquidate excessively. This occurs because there is a chance that the other bank is not fully informed and liquidates. Therefore, our model also allows for inefficient equilibrium runs on the borrower's assets on the part of well informed lenders, triggered by the first mover advantage. The effective path of play in this context-bad news ignored and excessive passivity, or good news ignored and excessive liquidation, or efficient decisions - depends upon how Nature distributes information across lenders.

The paper is organized as follows. Section 2 presents the model. In section 3 we derive the equilibrium strategies. We make the simplifying assumption that banks are treated symmetrically in a liquidation, thereby ensuring that a well informed bank always takes the socially efficient decision. This allows us to focus on the strategic aspects related to the ill informed bank "relying on the information of the other lender". Section 4 contains the above mentioned extension to why creditor passivity occurs during "financial scandals". Section 5 deals with the efficiency properties of the equilibria. Section 6 discusses

\footnotetext{
${ }^{6}$ To be precise, some situations may exhibit multiple equilibria, some of which are inefficient in the second-best sense described above.
} 
the limits to information sharing between banks that justify why information is not merged in our non-cooperative game. Section 7 extends the results to a game where lenders move in sequence, so that a rescheduling decision by the first mover is observable by the second. Section 8 concludes. Appendix 1 contains the proofs of the main results, while Appendix 2 analyzes the game with a first-mover advantage in liquidation.

\section{The model}

There are three periods, an entrepreneur with no endowment, and lenders. At date 0, the entrepreneur seeks financing for a project. Two lenders, henceforth the "banks", participate in equal measure to the provision of funds by means of debt contracts. Banks are small or the project is large, so that financing must be obtained from two lenders. The amount to be raised from each bank is normalized to 1. For each loan, the face value of the repayment is $B \geq 1$ and a bank receives this full amount if everything goes well. The credit market is competitive and lenders earn zero expected profit at equilibrium. To simplify, the opportunity cost of funds is zero.

With probability $\gamma$ the project is successful (good state of Nature). It is then completed by date 1 yielding a return that is sufficiently large to cover repayment of debt. With probability $1-\gamma$, the project runs into problems (bad state of Nature) and the loans cannot be paid back at date 1 as scheduled. A creditor then has two options. He can either foreclose on his loan or roll it over. Each loan share has liquidation value $L<1$ under the bad state of Nature - for instance some assets created by the debtor as means of realizing the project can be repossessed by the banks or the borrower has provided some outside collateral of equal value to each lender. Rescheduling by both banks allows the project to continue. Continuation yields each bank the random return $\widetilde{X}$ at date 2 , where $\widetilde{X}$ is distributed over the interval $[0,1]$ with cumulative distribution function $F(X) .{ }^{7}$ Denoting the expected return by $\bar{X}$, we assume $\bar{X}<L$ : from a collective standpoint, it is best to liquidate at date 1 unless information to the contrary becomes available.

\footnotetext{
${ }^{7}$ Since banks have equal share and the total return is less than the total faced value of debt, they share the return equally.
} 
Banks do not coordinate, for reasons to be explained below. When one bank reschedules and the other forecloses, the latter obtains $L+\varepsilon$ and the former $L-\varepsilon$, where $0 \leq \varepsilon<L$. Foreclosing by one bank disrupts the project, ultimately entailing liquidation, and $\varepsilon>0$ is the first-mover advantage in a run on the firm's assets. The parameter $\varepsilon$ depends on foreclosing costs or on the overlap between collateral. Alternatively, it reflects lenders' expectations about the advantage given to first movers by the legal and institutional setting.

At date 1, prior to the rescheduling decision, each bank independently obtains information about the value of continuation. The signal about $\widetilde{X}$ can be of two possible types: it is either the precise signal $\widetilde{S}_{p}$ or the coarse signal $\widetilde{S}_{c}$. The precise signal is more informative in the sense that, for any realizations $S_{p}$ and $S_{c}$, the conditional expectation about the value of continuation satisfies $E\left(\widetilde{X} \mid S_{p}, S_{c}\right)=E\left(\widetilde{X} \mid S_{p}\right)$, i.e., the coarse signal adds nothing to the precise signal in terms of information content, a feature that simplifies the discussion but is not essential to our results. ${ }^{8}$ With probability $\theta$ a bank observes the precise signal, with probability $1-\theta$ it observes the coarse one.

A bank does not know the content nor the type of signal received by the other bank, but it knows the probabilities with which sharp or coarse information is obtained. Moreover, the information received by the banks is non verifiable or soft. In particular, a bank observing $S_{p}$ may announce that the value of continuation is $E\left(\widetilde{X} \mid S_{p}\right)>L$, but it can offer no proof even if the announcement is true. Thus, any exchange of information at date 1 is cheap talk. The consequence is that information will not be shared because of the first-mover advantage in a liquidation run. We discuss further the limits to (non-cooperative) information aggregation between the two lenders in Section 5.

Accordingly, in the basic model, the banks act independently and simultaneously on the basis of the information each has received. The situation we have in mind is one where it is part of an equilibrium for the coarsely in-

\footnotetext{
${ }^{8}$ What matters, more generally, is that an ill informed lender knows that with some probability, because of superior information, another lender can make a decision which is more likely to be the right one.
} 
formed bank to disregard unfavorable information, i.e., the bank reschedules even though $E\left(\widetilde{X} \mid S_{c}\right)<L$. Intuitively, this requires that $\widetilde{S}_{p}$ be sufficiently more informative than $\widetilde{S}_{c}$ and that the probability $\theta$ of the other bank being better informed be sufficiently large. To make our point in as simple a set-up as possible, we therefore assume that the precise signal is in fact perfectly informative, i.e., $S_{p}=X$, while the coarse signal is totally uninformative, which we write as $S_{c}=\phi$. Observing the coarse signal is consequently always unfavorable since $E(\widetilde{X} \mid \phi)=\bar{X}<L$. The next section analyzes the rescheduling game.

\section{$3 \quad$ Rescheduling decisions}

To simplify the exposition further, we now assume that the first-mover advantage in foreclosure is close to zero. In effect, we will write all payoffs as if $\varepsilon=0$. By continuity, the actual equilibrium will be close to what we compute, but encumbered by "second order" terms. With $\varepsilon$ arbitrarily close to zero, when one bank reschedules and the other forecloses, the payoffs simplify to $L$ for each bank. In Appendix 2, we derive the banks' strategies when $\varepsilon$ differs from zero and discuss how this affects the equilibrium outcome.

Let $l i q$ and res refer to "liquidate" and "reschedule". Strategies are denoted by $\alpha$, the probability that a bank plays liq. Equilibrium strategies are denoted by $\alpha^{*}$. We write $\alpha(X)$ for the strategy played by a well informed bank which learns $X$; similarly, $\alpha(\phi)$ is the strategy played when ill informed. A bank's expected payoff is denoted by $u .^{9}$ Given the simplification that the first-mover advantage is arbitrarily small, bank $i$ 's expected payoff from playing $l i q$ does not depend on its information nor on bank $j$ 's strategy $(i, j=1,2 ; i \neq j)$. Thus,

$$
u_{i}\left(l i q, \alpha_{j} \mid \phi\right)=u_{i}\left(l i q, \alpha_{j} \mid X\right)=L, \quad \text { for all } X \text {. }
$$

This is not so for the expected payoff from playing res. If bank $i$ is informed,

\footnotetext{
${ }^{9}$ While this section describes the Bayesian equilibria for the simultaneous game, we introduce a sequence in section 6. The equilibrium concept is then Perfect Bayesian.
} 
its expected payoff is

$$
\begin{aligned}
& u_{i}\left(\text { res }, \alpha_{j} \mid X\right)= \\
& (1-\theta)\left[\alpha_{j}(\phi) L+\left(1-\alpha_{j}(\phi)\right) X\right]+\theta\left[\alpha_{j}(X) L+\left(1-\alpha_{j}(X)\right) X\right] .
\end{aligned}
$$

If it is ill-informed, the expected payoff from res is

$$
\begin{aligned}
& u_{i}\left(\text { res, } \alpha_{j} \mid \phi\right)= \\
& E\left\{(1-\theta)\left[\alpha_{j}(\phi) L+\left(1-\alpha_{j}(\phi)\right) X\right]+\theta\left[\alpha_{j}(X) L+\left(1-\alpha_{j}(X)\right) X\right]\right\} .
\end{aligned}
$$

In the last two equations, $\theta$ is the probability that bank $j$ is well informed. The difference between (2) and (3) is the expectation operator in the latter, since the bank whose payoff is represented in (3) does not know $X$. It is noteworthy that $u_{i}\left(r e s, \alpha_{j} \mid \phi\right)$ is increasing in $\theta$, the probability that the other lender is informed. ${ }^{10}$ Comparing (1) and (2), it is clear that liq is a weakly dominated strategy for an informed bank if $X>L$ occurs, since rescheduling affords a higher return than liquidation if the other bank also reschedules; while res is weakly dominated if $L>X$ holds (if $X=L$ there is a tie). At equilibrium, therefore, if bank $i$ is informed, one has

$$
\alpha_{i}^{*}(X)= \begin{cases}1 & \text { if } X<L, \\ 0 & \text { if } X \geq L .\end{cases}
$$

Note that this coincides with the socially optimal decision.

To derive the best response of an ill informed bank, define $Z=\max [X, L]$. This is the total return that would accrue from an unsuccessful project if the liquidation versus rescheduling decision was efficient (i.e., reschedule only if $X>L)$. The expected value of $Z$ is:

$$
\bar{Z} \equiv E(Z)=F(L) L+(1-F(L)) E(X \mid X \geq L) .
$$

Substituting in (3) and using (4), the payoff from res for an ill informed bank can then be rewritten as

$$
\begin{aligned}
& u_{i}\left(r e s, \alpha_{j} \quad \phi\right)= \\
&(1-\theta)\left[\alpha_{j}(\phi) L+(1-\alpha(\phi)) \bar{X}\right]+\theta \bar{Z} .
\end{aligned}
$$

\footnotetext{
${ }^{10}$ If the two lenders had different probabilities of being informed, $\theta_{i} \neq \theta_{j}$, as when having different sources of information, the expression for $u_{i}\left(\right.$ res, $\left.\alpha_{j} \mid \phi\right)$ would contain only $\theta_{j}$ in place of $\theta$. It is only the other's information probability that counts.
} 
Comparing (1) and (6), bank i's best response, when ill informed, depends on the other bank's strategy when the latter is also ill informed and on the likelihood of poor information. The expression in (6) is increasing in $\theta$ since $\bar{Z}>L>\bar{X}$. Accordingly, if $\theta$ is sufficiently large, it is best to play res and rely on the other bank to make the appropriate decision. Conversely, if $\theta$ is close to zero, the best move is to play liq. The expression in (6) is also increasing in $\alpha_{j}(\phi)$. The greater the probability that the other bank plays liq when ill informed, the safer it is to play res when one is also ill informed since the probability of a "wrong" rescheduling decision is smaller. Indeed, if bank $j$ always plays $l i q$ when ill informed (namely if $\alpha_{j}(\phi)=1$ ), playing res for sure is the unique best reply for bank $i$. As shown next, the equilibrium behavior of ill informed banks depends on the value of $\theta$.

Proposition 1 At equilibrium, for $\varepsilon=0$, well informed banks take the socially optimal decisions as in (4). Ill informed ones always reschedule their loan if

$$
\theta \geq \widehat{\theta} \equiv \frac{L-\bar{X}}{\bar{Z}-\bar{X}} .
$$

When $\theta<\widehat{\theta}$, there are two equilibria. In the symmetric equilibrium $M$, ill informed banks play a mixed strategy, rescheduling with the strictly positive probability

$$
1-\alpha^{*}(\phi)=\frac{\theta}{1-\theta}\left(\frac{\bar{Z}-L}{L-\bar{X}}\right), \quad i=1,2 .
$$

In the asymmetric equilibrium $P$, ill informed banks play pure strategies: one always reschedules, the other always liquidates.

Proof. See the Appendix.

The essence of the result is that banks sometimes rely on others to take the appropriate decision. The gamble, from the perspective of an ill informed bank, is that the other lender may have more precise information. When this is sufficiently likely (i.e., $\theta \geq \widehat{\theta}$ ), each bank, when ill informed, completely disregards its own unfavorable information and relies fully on the other bank to be better informed. In fact, "temporizing" through a rescheduling decision is then a dominant strategy - see the proof. 
When the likelihood of the other bank being well informed is small $(\theta<$ $\widehat{\theta})$, there are two possibilities. In the pure strategy equilibrium $P$, one bank is passive and "delegates" to the other lender the liquidation versus rescheduling decision. In turn, the lender in charge always forecloses when ill informed, completely discounting the possibility that the other bank may have obtained favorable information. ${ }^{11}$ In the symmetric strategy equilibrium $M$, an ill informed bank is indifferent between rescheduling or foreclosing. The greater the likelihood that the other bank is well informed, the larger the probability of rescheduling, i.e., of relying on the decision to the other lender. ${ }^{12}$ As a matter of computation, $\left(1-\alpha^{*}(\phi)\right)$ is increasing in $\theta$ and takes value 1 when $\theta$ reaches the threshold value $\widehat{\theta}$.

\section{A digression on "financial scandals"}

We may ask what happens when, as in the case of recent financial scandals, some informed lenders are also collusive with borrowers - for instance, the Italian firm Parmalat ${ }^{13}$ scandal and similar examples throughout the world such as the Enron scandal in the U.S., where banks have gone as far as helping their customers with accounting manipulation. ${ }^{14}$ Similarly, one may also consider the evidence on "related lending" in Mexico (La Porta et al. 2003) or the behavior of State controlled banks (the so-called "soft budget

\footnotetext{
${ }^{11}$ When $\varepsilon>0$ and is sufficiently large, the equilibrium $P$ ceases to exist, although the equilibrium in mixed strategies remains. For $\theta$ small, then, the pure strategy equilibrium is for both lenders to liquidate. This issue is briefly discussed in the appendix.

${ }^{12}$ With different probabilities of being informed, $\theta_{i} \neq \theta_{j}$, the expression for $i^{\prime}$ s equilibrium mixed strategy would display $\theta_{j}$ replacing $\theta$.

13 "The vast bulk of the more than $\$ 10$ billion in public and private debt placed by Parmalat since 1997 was arranged by big banks, including Bank of America, Citigroup, Morgan Stanley and Deutsche Bank. The Securities and Exchange Commission (SEC), America's main securities regulator, is examining whether American banks deliberately ignored irregularities in Parmalat's finances when they sold Parmalat bonds to (mainly American) investors." ( The Economist, January 22, 2004: "Parmalat: Skimming off the cream"; http://www.economist.com/finance)

${ }^{14}$ For instance, Citigroup manipulated written records of its transactions with Enron "to allow the company to improperly avoid the requirements of accounting rules and the law, thus keeping $\$ 125$ million in debt off its books" ("Citigroup is linked to a deal that let Enron skirt rules", The New York Times, July 23, 2002.)
} 
constraint" problem).

Most of these stories share the property that large and supposedly informed lenders have been biased towards renewing loans to particular borrowers that later on defaulted. Large banks are inclined to lend to borrowers that are customers in other business from which they get huge fees. They often act as leading creditors in syndicated loans, so that, granting a larger share of the loan than other smaller lenders, they gain preference from borrowers as providers of other lucrative services. Conflicts of interests also arise when international institutions are involved, as when the IMF decides to roll over a country's debt, leaving outside investors wondering wether the deal reflects a positive view of the borrower's solvability or rather is the result of broader concerns - we again refer the reader to Blustein (2005). Our model can be used to sketch an analysis of the circumstances where uninformed lenders (for instance small debtholders) participate in financing a loan together with informed lenders who can possibly enjoy private benefits from lending to a particular borrower. The question is not so much to explain why biased lenders reschedule their share of loans, but rather to explain why uninformed lenders accept holding to their own share of debt rather than exiting when troubles are in sight.

To start with, assume that only two lenders are involved, so as not to upset the framework of analysis. Assume that lender 1 is an arm-length lender, who is unable to collect any information in addition to the publicly available one, namely he can only receive the coarse signal; his type is common knowledge. Lender 1's strategy is denoted by $\alpha_{1}$. Lender 2 by contrast has superior access to information and can either be informed, with probability $\theta$, or uninformed. The utility lender 2 gets from continuation when he is uninformed is now modified as follows:

$$
\tilde{u}_{2}(r e s \mid \phi)=\alpha_{1} L+\left(1-\alpha_{1}\right) \bar{X}+\lambda
$$

Here $\lambda$ is a random variable, privately observed by lender 2, and with values $\lambda=0$ or $\lambda=1$ depending on the private benefits from continuation accruing to lender 2 when he is uninformed. The state of Nature where $\lambda=1$ is the case where lender 2 is of the "biased" type. Let $q$ denote the commonly known probability that $\lambda=0$ is realized. As a simplification we assume that 
similar private benefits do not arise when lender 2 is informed, bearing no consequences on the main argument, so that

$$
\tilde{u}_{2}(\text { res } \mid X)=\alpha_{1} L+\left(1-\alpha_{1}\right) X
$$

Clearly, since $\tilde{u}_{2}(l i q \mid X)=L$, lender 2 always takes the efficient decision when he is perfectly informed (again by elimination of weakly dominated strategies). If he is uninformed he takes the liquidation decision only if $\lambda=0$, while if $\lambda=1$ he reschedules.

Given this information about lender 2's strategies, the expected utility of lender 1 from rescheduling is:

$$
\tilde{u}_{1}(\text { res })=q[\theta \bar{Z}+(1-\theta) L]+(1-q)[\theta \bar{Z}+(1-\theta) \bar{X}] .
$$

His utility from liquidating is $\tilde{u}_{1}(l i q)=L$. lender 1 is passive if he reschedules in spite of a positive probability that lender 2 is biasaed. By comparing $\tilde{u}_{1}($ res $)$ and $L$, Lender 1 reschedules provided

$$
q>\frac{L-\bar{X}-\theta(\bar{Z}-\bar{X})}{(1-\theta)(L-\bar{X})} \equiv q_{0}(\theta) .
$$

When $q$ is larger than $q_{0}(\theta)$, lender 1 behaves passively and reschedules, giving lender 2 the chance to be decisive. In this case, the biased lender earns his private benefit by inducing rescheduling even if he has no (favorable) information. The arm's length lender 1, in a sense, accepts the risk of "being fooled" by lender 2. It is only when $q$ is lower than the threshold value, $q_{0}(\theta)$, that lender 1 never reschedules (and hence there is no scope for the biased lender 2 rescheduling either). Otherwise stated, when there is a large probability that the informed lender will seek private benefits, there is an implicit check on this lender: even if he results to be of the "bad" type the uninformed lenders adopt an exit strategy by liquidating.

In essence, the story does not change much if one introduces additional arm's length lenders who are uninformed. Assume that lender 1's debt share is split in $n$ equal parts held by $n$ "replicas" of lender 1 . The payoff from rescheduling for each of these lenders, when the $n-1$ other uninformed lenders reschedule, is then simply one $n$th of $\tilde{u}_{1}($ res) as defined in (11); his payoff 
from liquidating is $L / n$. Thus, $q>q_{0}(\theta)$ again ensures that rescheduling is an equilibrium strategy for the arm's length lenders.

Similarly, one can introduce a second lender who can be informed or not, but also biased or unbiased. This lender will act in a similar way as lender 2 in the two lenders case, only now he will know that his own biased rescheduling may be nullified by the other informed lender when he is of the unbiased type. If bias (private benefits) is correlated across lenders, the replica-lenders of lender 2 will tend to use the same strategies and "fool the market" formed by the uninformed lenders. Continuing, one may reintroduce replicas of arm's length lenders, simulating an environment where many small debtholders and one or few large institutional investors buy debt issued by a single large debtor. The large investors may be biased or unbiased and have access to superior information. The small debtholders buy bond-like securities with an attached risk of being fooled by the actions of the large investors. In spite of this, they rationally gamble and reschedule when they should have refrained from doing so if there had been no such large partners. That the large debthoder be liquidation-pivotal is crucial here (in order to trigger efficient liquidations with positive probability), while the small debtholder, as far as he gets $L / n$, will adopt the same strategy wether he is pivotal or not in liquidation.

It is noteworthy that $q_{0}(\theta)$ is decreasing in $\theta$ : for the same value of the parameter $q$ (probability that "lender 2 " be unbiased) uninformed lender 1 is more likely to reschedule if $\theta$ is large: small bondholders are caught in rescheduling with higher probability in an economy where collusive lenders, if they exist, are highly privileged in information acquisition. ${ }^{15}$

\section{$5 \quad$ Inefficiency}

We now revert to the model of section 3 and discuss the nature of the inefficiencies in equilibrium. Inefficiency compared to the first-best with shared

\footnotetext{
${ }^{15}$ As La Porta et al. (2003) argue "bankers know more about related borrowers than unrelated ones because they are represented on the borrower's Board of directors and share in the day-to-day management of the borrower". In this sense external investors may infer that banks owning shares of their dbtors are both informed and biased. A very low $q$ and a very high $\theta$ may coexist in these situations.
} 
information is not surprising. Still, it is of interest to explore how the nature and extent of the inefficiency is affected by the amount of information in the system. Moreover, while the perfect sharing of information represents an obvious benchmark, we also ask whether the equilibria can be improved upon even though information is not shared. For instance, one may invoke the need for contracts or guidelines that provide bank managers with incentives for prudence in large loans, dictating liquidation if there is no news changing a debtor's score. Conversely, as advocated (especially in Europe) by supporters of State or community owned banks, guidelines may be biased towards more rescheduling in an attempt to internalize the political effects of foreclosure. ${ }^{16}$ More generally, one may ask whether a pre-designed plan of action can be substituted to the one dictated by the equilibrium strategies so as to improve efficiency.

The facial value of each loan is $B$ (i.e., $B=1+\rho$ where $\rho$ is the rate of interest on the debt contract) and by assumption the value of a successful project is sufficiently large to reimburse each lender. Let $\bar{Y}$ denote the amount that each lender expects to recuperate from an unsuccessful project-i.e., one that will not be completed at date 1. Recall that a project is successful with probability $\gamma$. In a perfectly competitive credit market, banks earn zero ex ante expected profits so that $B$ satisfies

$$
\gamma B+(1-\gamma) \bar{Y}=1
$$

The larger $\bar{Y}$, the smaller $B$ (equivalently, the smaller $\rho$ ). We measure inefficiency by how small $\bar{Y}$ is.

In terms of the lenders' strategies, and written as a function of $\theta$, the amount recuperated on average by each lender is

$$
\begin{aligned}
\bar{Y}(\theta)= & \theta^{2} \bar{Z}+\theta(1-\theta)\left[\widehat{\alpha}_{2} L+\left(1-\widehat{\alpha}_{2}\right) \bar{Z}\right]+(1-\theta) \theta\left[\widehat{\alpha}_{1} L+\left(1-\widehat{\alpha}_{1}\right) \bar{Z}\right] \\
& +(1-\theta)^{2}\left[\left(1-\left(1-\widehat{\alpha}_{1}\right)\left(1-\widehat{\alpha}_{2}\right)\right) L+\left(1-\widehat{\alpha}_{1}\right)\left(1-\widehat{\alpha}_{2}\right) \bar{X}\right],
\end{aligned}
$$

where $\widehat{\alpha}_{i}$ is the strategy $\alpha_{i}(\phi)$ when ill informed. In the above expression, each bank plays the socially optimal - and equilibrium - strategy when well

\footnotetext{
${ }^{16}$ For an assessment of the effects of government ownership of banks see La Porta, Lopez-de-Silanes and Shleifer (2002).
} 
informed. The derivation of (13) is straightforward. The expected return $\bar{Z}$ is obtained when both banks are well informed or when only one is, which occurs with probability $2 \theta(1-\theta)$, and the other reschedules. When both banks are ill informed, the total return from an unsuccessful project is $L$ if at least one bank liquidates, otherwise it is on average $\bar{X}$.

In a first best with perfectly aggregated information, the amount expected to be recuperated is

$$
\bar{Y}^{*}(\theta)=(1-\theta)^{2} L+\left(1-(1-\theta)^{2}\right) \bar{Z} .
$$

When information is shared, $\bar{Z}$ is expected to be recuperated if at least one of the lenders is informed, hence with probability $1-(1-\theta)^{2}$. When none is informed, the project is appropriately liquidated.

Denote the equilibrium outcome by $\bar{Y}^{e}(\theta)$. From proposition 1, when $\theta \geq \widehat{\theta}$

$$
\bar{Y}^{e}(\theta)=\bar{Y}_{I I}(\theta) \equiv(1-\theta)^{2} \bar{X}+\left(1-(1-\theta)^{2}\right) \bar{Z} .
$$

The subscript in the middle expression emphasizes that in equilibrium both lenders always reschedule; that is, we set $\widehat{\alpha}_{1}=\widehat{\alpha}_{2}=0$ in (13). Note that $\bar{Y}_{I I}(\theta)$ is always smaller than $\bar{Y}^{*}(\theta)$, provided $\theta$ is not equal to one. This means that inefficiency with respect to the first best arises out of bank passivity in case $\theta>\widehat{\theta}$ (the pure strategy equilibrium region where ill informed banks always reschedule at unison).

When $\theta<\widehat{\theta}$, the outcome depends on which equilibrium we pick. In the pure strategy equilibrium, when both banks are ill informed, one reschedules and the other liquidates. Hence,

$$
\bar{Y}^{e}(\theta)=\bar{Y}_{P}(\theta) \equiv(1-\theta) L+\theta \bar{Z} .
$$

In the mixed strategy equilibrium, both lenders play the same strategy and

$$
\begin{aligned}
\bar{Y}^{e}(\theta)= & \bar{Y}_{M}(\theta) \equiv \theta^{2} \bar{Z}+2 \theta(1-\theta)[\widehat{\alpha} L+(1-\widehat{\alpha}) \bar{Z}] \\
& +(1-\theta)^{2}\left[\left(1-(1-\widehat{\alpha})^{2}\right) L+(1-\widehat{\alpha})^{2} \bar{X}\right],
\end{aligned}
$$

where $\widehat{\alpha}$ is the optimal strategy $\alpha(\phi)$ defined in proposition 1 . Observe that for $\theta=0$ one has $\widehat{\alpha}=1$ and hence $\bar{Y}^{e}(\theta)=\bar{Y}^{e}(\theta)=Y^{*}=L$, so that there is no loss of efficiency with respect to the first best. The same holds if $\theta=1$. 
Comparing with the first-best amount in (14), therefore, one can see that $\bar{Y}^{e}(\theta) \leq \bar{Y}^{*}(\theta)$, with strict inequality when $\theta \in(0,1)$. There is maximum waste of information when the probability that individual banks are well informed is neither too large nor too small. When the information is on average either very good ( $\theta$ close to unity) or very bad ( $\theta$ close to zero), the social loss from the non sharing of information is negligible. Relying on the other bank to be well informed has no social cost if indeed the other bank is very likely to be informed. Conversely, when the likelihood is small, at least one bank will almost be certain to liquidate - this is the bank "in charge" in equilibrium $P$ or both banks in equilibrium $M$, since $\alpha(\phi)$ in (8) then approaches unity.

Consider now the nature of the inefficiency. When $\theta \geq \widehat{\theta}$, ill informed banks always reschedule. Rescheduling may therefore occur even though both banks have unfavorable - albeit imprecise - information. Compared to the first best, the problem is therefore too much rescheduling. By contrast, when $\theta<\widehat{\theta}$, inefficient rescheduling never occurs in the pure strategy equilibrium, but there is inefficient liquidation. The bank "in charge" may then foreclose even though the other lender observed $X \geq L$. In the mixed strategy equilibrium, both types of inefficiencies occur. Which of these two equilibria is socially preferable? In the proof of the next proposition, we show that the pure strategy equilibrium is socially preferable, i.e., $\bar{Y}_{P}(\theta)>\bar{Y}_{M}(\theta)$ for $\theta \in(0, \widehat{\theta})$.

A more general question is whether a Pareto improvement could be achieved by imposing rescheduling strategies on banks, subject to the constraint that they are consistent with the banks' private information. Second-best optimal strategies potentially differ from the equilibrium ones only in the event that banks are ill informed. To characterize the socially optimal strategies, it is therefore sufficient to choose $\widehat{\alpha}_{1}$ and $\widehat{\alpha}_{2}$ in (13) so as to maximize $\bar{Y}(\theta)$.

Proposition 2 The following strategies are second-best optimal, subject to the constraint that lenders cannot credibly share information: if $\theta \geq \widehat{\theta}, \widehat{\alpha}_{1}=$ $\widehat{\alpha}_{2}=0$; if $\theta<\widehat{\theta}, \widehat{\alpha}_{1}=1$ and $\widehat{\alpha}_{2}=0$ or $\widehat{\alpha}_{1}=0$ and $\widehat{\alpha}_{2}=1$.

Proof. See the Appendix. 
The result is surprising. When lenders obtain information that cannot be shared and if the likelihood of information is sufficiently high $(\theta \geq \widehat{\theta})$, there is indeed excessive rescheduling compared to the ideal of perfectly aggregated information. However, given the constraint that information cannot be shared, rescheduling decisions are socially optimal in a second-best sense. Put differently, in equilibrium, there is not excessive reliance on others being well informed. For instance, the outcome would be worse if ill informed banks always acted myopically, foreclosing on the basis of the imprecise but unfavorable information $\phi .{ }^{17}$ When $\theta<\widehat{\theta}$, the pure strategy equilibrium is second-best efficient. It is socially efficient for the bank "in charge" to act myopically — at the risk of inefficient liquidation - and for one bank to fully rely on the other lender's decision. Inefficient rescheduling in a second-best sense therefore only arises in the mixed strategy equilibrium, which requires a sufficiently small probability of banks being well informed.

\section{Limits to information sharing}

To show that banks cannot credibly communicate in our set-up, we expand the set of actions at date 1 to allow for a communication game. One can imagine that, prior to the play of the rescheduling decisions, banks make announcements, $m_{i}$, of the form $m_{i}=\hat{X}$ or $m_{i}=\phi$, after which they play "reschedule" or "liquidate" as described above (alternatively, the banks could announce their intention to play "reschedule" or "liquidate"). Banks have conflicting interests when there is a first-mover advantage to the bank which forecloses while the other reschedules: the former gets $L+\varepsilon$, the latter $L-\varepsilon$. The following result justifies the analysis of the full game under the assumption that no communication between banks is possible.

Lemma 1 If a communication game is played at date 1, it is a dominant strategy to announce $m_{i}=\hat{X}$ such that $\hat{X} \geq L+\varepsilon$.

The result is obvious. If a bank indeed learned $X$ satisfying the inequality, it would like to convince the other bank that continuation is profitable for

\footnotetext{
${ }^{17}$ We would then have $\bar{Y}(\theta)=\left(1-\theta^{2}\right) L+\theta^{2} \bar{Z}$, which is easily seen to be less than $\bar{Y}_{I I}(\theta)$ when $\theta \geq \widehat{\theta}$.
} 
both of them. However, a bank learning $X$ such that $X<L-\varepsilon$ would also gain from making the same announcement if it were believed (which requires that the other is ill informed), since it would be the first mover in liquidation. Similarly, a bank learning $\phi$ cannot gain by announcing that it received a poor but unfavorable signal. For instance, suppose the two banks are ill informed and that each truthfully announces $\phi$, prompting liquidation at the next stage. Then one bank would have been better off announcing a favorable $X$ and be the first mover should the announcement be believed. Thus, in equilibrium, favorable announcements will never be believed and will be equivalent to being told nothing. In the terminology of cheap-talk games, announcements are neither self-committing nor self-signaling, hence are not credible (see Farrell and Rabin, 1996).

One objection to the infeasibility of credible communication is the possibility, contrary to what we assumed, that a lender could commit sufficient funds to buy out the other lender's claim. A lender with favorable information would make an offer, with a commitment to execution, that could signal his information. Leaving aside the problem of ensuring commitment to such an offer, it would nevertheless still be the case that information is not efficiently shared. The problem is that banks are asymmetrically informed and each one wants to sell high or purchase cheap. ${ }^{18}$

To illustrate, suppose offers to buy out the other bank's loan can be modeled as a second-price auction. Each bank announces a price $b$ at which it would be ready to sell its claim and up to which it would be willing to buy out the other. ${ }^{19}$ If $b_{j}>b_{i}$, the bank with bid $b_{j}$ purchases the other bank's loan for a price equal to $b_{i}$. Both loans therefore end up in the hands of a single lender, who then makes the decision regarding rescheduling (if there is a tie, a coin is flipped to pick the winner). If bids reflected true values conditional on each bank's private information, an ill informed bank would bid $b(\phi)=L$ and a well informed bank $b(X)=\max (L, X)$. Such bids would reveal all relevant information and rescheduling decisions would therefore be

\footnotetext{
${ }^{18}$ This is a variant of the Myerson and Satterthwaite (1983) impossibility result for bilateral trading games.

${ }^{19}$ There is no improvement if the strategies consisted of posting only a buying price or no price (and implicitly fixing a non revealed selling price).
} 
efficient. However, it is easily seen that the above bidding strategies cannot be part of an equilibrium.

Consider an ill informed bank which expects the other lender to play according to the above strategies. Bidding $b<L$ is clearly a dominated strategy, while the expected net payoff from bidding $b>L$ is

$$
[1-\theta+\theta F(L)] L+\theta \int_{L}^{b} X f(X) d X+\theta(1-F(b)) b
$$

The expression in brackets is the probability that the other lender bids $L$, either because he is ill informed or is well informed but $X \leq L$. In this case, a bid $b>L$ wins the auction and the winner obtains assets which can be inferred to be worth $2 L$ and for which a price $L$ is paid. The second term is the expected gain against an informed player whose bid is above $L$ but below $b$ (the buyer infers that the assets are worth $2 X$, for which $X$ is paid). The third term is the payoff from losing the auction and selling one's claim at price $b$. It is easily checked that the above expression is strictly increasing in $b$ in a neighborhood of $b=L$. An ill-informed player expecting the other player to bid "truthfully" would therefore want to overbid.

It can be shown that the equilibrium of this bidding game involves mixed strategies, with overbidding, both for an ill informed and a well informed lender. Hence, information will not be perfectly shared and the winner of the bidding game will still make inefficient rescheduling decisions. ${ }^{20}$

\section{Herding}

Our results bear some similarity with so-called herding phenomena. However, the mechanism leading to a "wrong" outcome with herding is of a very different nature. Herding (see for instance Banerjee 1992) occurs when players who receive private signals observe the actions taken by other players and update accordingly. In such a setup, the first player, so to speak, can determine a cascade of optimal deviations from the actions dictated by the

\footnotetext{
${ }^{20}$ Overbidding occurs in equilibrium as in Burkart (1995), but in the context of a common-value auction as in Engelbrecht-Wiggans et al. (1983).
} 
private signals, even when the information received by players, if merged, would point towards a superior solution.

In our case, observing other players' actions is inessential. An ill informed bank knows that, if it reschedules, its mistake can be corrected by the better informed lender, when there is one, but not if it forecloses. This suffices to gamble against information that is unfavorable but poor. Indeed, modifying our set-up so as to introduce a sequence of moves has no effect on the results. Suppose one bank, say bank 1 , moves first. Denote its strategy by $\widehat{\alpha}_{1}(\cdot)$ where the dot refers to the bank's private information. Bank 2 moves after observing the action of bank 1 . Its strategy is described by $\widehat{\alpha}_{2}($ liq, $\cdot)$ and $\widehat{\alpha}_{2}($ res,$\cdot)$, where again the dot is the bank's private information and where liq and res refer to bank 1's action. We have the following result.

Proposition 3 Let $\alpha_{1}^{*}(\cdot)$ and $\alpha_{2}^{*}(\cdot)$ be equilibrium strategies of the simultaneous game, where the argument is $\phi$ or the realization of $\widetilde{X}$. Then $\widehat{\alpha}_{1}(\cdot)=\alpha_{1}^{*}(\cdot)$ and $\widehat{\alpha}_{2}($ liq,$\cdot)=1, \widehat{\alpha}_{2}($ res,$\cdot)=\alpha_{2}^{*}(\cdot)$ are equilibrium strategies of the sequential game where bank 1's play of res or liq is observed by bank 2.

Proof. See the Appendix.

Bank 2 is now better informed than when moves are simultaneous, but the outcome is not improved. The intuition is that bank 2's action matters only when bank 1 plays res, as in the simultaneous game. If bank 2 is well informed, it chooses the socially efficient action, again as in the simultaneous game. In one class of equilibria, an ill informed bank 2 replicates res because the play of res by bank 1 represents "good news". ${ }^{21}$ Thus, an ill informed bank 2 plays res when its decision matters. For bank 1, the play of res therefore has the same expected payoff as in the simultaneous game.

\section{Conclusion}

The notion that loan arrangements may result in excessive lending is not new. This takes different forms depending on the context. The financing of

\footnotetext{
${ }^{21}$ Rescheduling by bank 1 is good news if $\theta$ is large, since the possibility that the bank rescheduled even though ill informed is then small. It is also good news if $\theta$ is small and bank 1 plays res only when well informed.
} 
projects with negative expected present value (De Meza and Webb, 1987) or the provision of loans that allow managers to pursue inefficient projects in the future (Hart and Moore, 1995) are just two examples. Similarly, inefficient monitoring may hamper the ability to make the efficient financing decisions at the rescheduling stage. "Gambling for resurrection" of the borrower has also been claimed as a possible explanation of creditor's passivity in transition economies (see Perotti (1993).Other theories of overlending are found in Rajan (1994) and in Thakor (2005). Rajan's (1994) argument, roughly speaking, is based on bank mangers' short-termism and on their ability to manipulate market perceptions by refinancing debtors that are in trouble so as to hide losses. This induces overlending during booms and credit crunches during recessions (Mitchell (2001) also argues that loss hiding by banks be a motivation for creditor passivity). Thakor (2005) explores the effects of the banks' practice of engaging in loan commitments as a form of borrower's insurance against future credit rationing in the event of interest rates increases. He shows that loan commitments reduce inefficient credit rationing during economic downturns though they generate excessive lending in good times.

The idea explored in the present paper is that inefficiencies may arise at the rescheduling stage because lenders rationally decide to disregard bad signals. There is excessive rescheduling in the sense that ex post, were the information available to lenders revealed, it could be verified that all lenders had bad news and all lenders nevertheless decided to reschedule. Our argument bears some similarity with so-called herding phenomena. However, the similarity is only apparent: in our game the results do not impinge upon a player observing the actions of other players. An ill informed bank, because of the chain of events triggered by foreclosure, knows that its mistake in rescheduling can be corrected by better informed lenders. This suffices to gamble against privately observed bad signals, provided the first-mover advantage in a liquidation run is not too large. Obviously, this depends on whether loans are collateralized and more generally on the extent to which creditor rights are protected.

In practice, foreclosing is a drastic decision only if creditor rights are highly protected and repossession of the debtor's assets is swift and frictionless. This is not so in most industrialized countries and maybe even less so in 
less developed ones. Prevailing codes ensure that debtor rights are preserved under liquidation, or that debtors can appeal to special protection such as Chapter 11 in the U.S., based on the idea that liquidation of viable firms may occur due to market imperfections. This is clearly not the place to resume the rich debate on the design of optimal creditors' rights, liquidation and bankruptcy. We point out, however, that a loan's liquidation value in the model should be interpreted as reflecting the payment expected by a lender, given the collateral arrangement, if any, and given the prevailing legislation and efficiency of the legal system.

In our model each lender is pivotal if he liquidates, by virtue of what we have termed "strong complementarity" of the liquidation decision. In the real world, when debt shares are strongly asymmetric or when the number of lenders is large, or both, a lender may not be so pivotal. If non-pivotality means that liquidation by a small lender does not trigger liquidation of the project - meaning, in our notation, that the lender goes away with value $L$ then our analysis need not be modified. The case is different if non pivotality means that a lender cannot get away with his share of the liquidation value and is forced to stay in the loan and wait the end of the restructuring process (e.g., when a debtor succeeds in enforcing a moratorium on debt payments). In our model this implies that a lender is forced to go on and wait for the end of period 2. One can model this by introducing a probability of not being pivotal when a lender is the only one to refuse rescheduling. The strategy of the perfectly informed lender is not changed: it is always a dominant strategy to reschedule only if $X>L$ has been observed. Since liquidation entails some probability of continuing, it will to some extent, though not completely, replace the choice of rescheduling for the ill informed bank.

Finally, there are other examples of games where players do not use all of the information available to them. In Brandenburger and Polak (1996), managers maximize the value of the firms' shares by taking the actions they would take if their information did not differ from that of market participants. The point is that managers choose suboptimal actions even though they have superior information. The finance literature also deals with various kinds of inefficient management that tries to please analysts (see for instance Degeorge, Patel and Zeckhauser, 1999 and 2005, and the references therein). 
In a voting context, Feddersen and Pesendorfer (1996) analyze a game where voters abstain if they are ill informed, for fear of being pivotal.

\section{Appendix 1}

Proof of proposition 1: From (1) and (6), when ill informed, bank $i$ plays res if

$$
(1-\theta)\left[\alpha_{j}(\phi) L+\left(1-\alpha_{j}(\phi)\right) \bar{X}\right]+\theta \bar{Z} \geq L .
$$

Consider first the case where $\theta \geq \widehat{\theta}$ as defined in the proposition. The above condition is then satisfied with $\alpha_{j}(\phi)=0$. Moreover, the left-hand side of (19) is increasing in $\alpha_{j}(\phi)$ because $L>\bar{X}$. Hence, the condition holds for all $\alpha_{j}(\phi)$, which means that res is a dominant strategy for bank $i$. This proves the first part of the proposition. When $\theta<\widehat{\theta}$, condition (19) does not hold if $\alpha_{j}(\phi)=0$. The best response to the pure strategy res is therefore the pure strategy liq. Now, (19) is satisfied as a strict inequality if $\alpha_{j}(\phi)=1$ (since $\bar{Z}>L$ and given $\theta>0$ ). Thus, res is itself the best response to liq, proving equilibrium $P$. From this last argument, when $0<\theta<\widehat{\theta}$, there exists $\alpha_{j}(\phi) \in(0,1)$ such that $(19)$ holds as an equality. Solving for $\alpha_{j}(\phi)$ yields (8) and proves equilibrium $M$.

Proof of proposition 2: The optimal $\alpha_{1}$ and $\alpha_{2}$ maximize $\bar{Y}(\theta)$ as defined in (13). Let $\mu_{i}$ be the multiplier associated with the constraint $\alpha_{i} \leq 1$ and $\nu_{i}$ the multiplier associated with $\alpha_{i} \geq 0, i=1,2$. The Lagrangian is

$$
\mathcal{L}=\bar{Y}(\theta)+\mu_{1}\left(1-\alpha_{1}\right)+\nu_{1} \alpha_{1}+\mu_{2}\left(1-\alpha_{2}\right)+\nu_{2} \alpha_{2}
$$

The necessary conditions for a maximum are the Kuhn-Tucker first-order conditions

$$
\begin{aligned}
& \partial \mathcal{L} / \partial \alpha_{1}=(1-\theta)\left[(1-\theta)(L-\bar{X})\left(1-\alpha_{2}\right)-\theta(\bar{Z}-L)\right]-\mu_{1}+\nu_{1}=0 \\
& \partial \mathcal{L} / \partial \alpha_{2}=(1-\theta)\left[(1-\theta)(L-\bar{X})\left(1-\alpha_{1}\right)-\theta(\bar{Z}-L)\right]-\mu_{2}+\nu_{2}=0
\end{aligned}
$$

together with complementary slackness and non-negativity of the multipliers,

$$
\mu_{i}\left(1-\alpha_{i}\right)=\nu_{i} \alpha_{i}=0, \mu_{i} \geq 0, \nu_{i} \geq 0, i=1,2
$$


When $\theta>\widehat{\theta},(1-\theta)(L-\bar{X})\left(1-\alpha_{i}\right)-\theta(\bar{Z}-L)<0$ for all $\alpha_{i}$. Hence, there is only one solution to (20), (21) and (22) and it involves $\nu_{i}>0$, implying $\alpha_{i}=0, i=1,2$. We henceforth discuss the case $\theta<\widehat{\theta}$.

We first discard the possibility of corner solutions of the form $\alpha_{1}=\alpha_{2}=0$ or $\alpha_{1}=\alpha_{2}=1$. Consider the first possibility. With $\alpha_{1}=\alpha_{2}=0$, the term in brackets in $(20)$ and $(21)$ is positive since $(1-\theta)(L-\bar{X})-\theta(\bar{Z}-L)>0$ for $\theta<\widehat{\theta}$. The conditions are therefore satisfied only if $\mu_{1}>0$ and $\mu_{2}>0$, which in turn implies $\alpha_{1}=\alpha_{2}=1$, a contradiction. Similarly, noting that the term in brackets is negative if $\alpha_{1}=\alpha_{2}=1$, the conditions are then satisfied only if $\nu_{1}>0$ and $\nu_{2}>0$, which implies $\alpha_{1}=\alpha_{2}=0$, again a contradiction.

We now show that the conditions are satisfied by a corner solution of the form $\alpha_{1}=1$ and $\alpha_{2}=0$. By the above argument, $\alpha_{2}=0$ in (20) implies $\mu_{1}>0$ and therefore $\alpha_{1}=1$. In (21), $\alpha_{1}=1$ implies $\nu_{2}>0$, hence $\alpha_{2}=0$. There is therefore a corner solution, as stated, for appropriate values of $\mu_{1}$ and $\nu_{2}$. This corner solution corresponds to equilibrium $P$ and it yields $\bar{Y}_{P}(\theta)$ as defined in (16).

Finally, it is easily seen that the term in brackets in (20) and (21) is zero if $\alpha_{1}=\alpha_{2}=\alpha(\phi)$, where the latter is as defined in (8). Together with $\mu_{i}=\nu_{i}=0, i=1,2$, this therefore constitutes another possible solution to the set of necessary conditions. Furthermore, it is the only interior solution. It corresponds to equilibrium $M$ and yields $\bar{Y}_{M}(\theta)$.

To conclude the proof for the case $\theta<\widehat{\theta}$, we therefore need to compare $\bar{Y}_{P}(\theta)$ and $\bar{Y}_{M}(\theta)$. >From (8), substitute for $\widehat{\alpha}=\alpha(\phi)$ in (17) so that

$$
\bar{Y}_{M}(\theta)=L+\left[\theta^{2}(\bar{Z}-L)(\bar{Z}-\bar{X})\right] /(L-\bar{X}) .
$$

Define

$$
h(\theta) \equiv \bar{Y}_{M}(\theta)-\bar{Y}_{P}(\theta)=\left[L+\frac{\theta^{2}(\bar{Z}-L)(\bar{Z}-\bar{X})}{(L-\bar{X})}\right]-[(1-\theta) L+\theta \bar{Z}] .
$$

This function is a quadratic in $\theta$, with roots at $\theta=\widehat{\theta}=(L-\bar{X}) /(\bar{Z}-\bar{X})$ and $\theta=0$. The expression is also strictly convex, hence $h(\theta)<0$ when $\theta \in(0, \widehat{\theta})$. Thus, $\bar{Y}_{P}(\theta)>\bar{Y}_{M}(\theta)$ and the optimum is the corner solution $\alpha_{1}=1$ and $\alpha_{2}=0$. 
Proof of proposition 3: When bank 1 chooses liq, bank 2 cannot affect the outcome and it is therefore a best response to also choose liq, hence $\widehat{\alpha}_{2}($ liq,$\cdot)=1$. Obviously, $\widehat{\alpha}_{1}(X)=\widehat{\alpha}_{2}($ res,$X)=\alpha(X)$, i.e., well informed banks choose the socially efficient action (when their action matters). Thus, we need only discuss $\widehat{\alpha}_{1}(\phi)$ and $\widehat{\alpha}_{2}($ res,$\phi)$. In the simultaneous game (and given that the other bank behaves efficiently when well informed), bank 2 prefers res to $l i q$ if

$$
\left.(1-\theta)\left[\alpha_{1} L+\left(1-\alpha_{1}\right)\right) \bar{X}\right]+\theta \bar{Z} \geq L
$$

where $\alpha_{1}$ is short-hand for $\alpha_{1}(\phi)$. In the sequential game, after the play of res by bank 1 , res is preferred to liq by bank 2 if

$$
\frac{\theta(1-F(L)) E(X \mid X \geq L)+(1-\theta)\left(1-\alpha_{1}\right) \bar{X}}{\theta(1-F(L))+(1-\theta)\left(1-\alpha_{1}\right)} \geq L,
$$

where $\alpha_{1}$ is short-hand for $\widehat{\alpha}_{1}(\phi)$. The left-hand side is the expected payoff from playing res, given that bank 2 observed $\phi$ and the play of res by bank 1 (the probability of the latter is the numerator of the expression). Now, from (5), substitute for $\bar{Z}$ in (23), which then writes as

$$
\left.(1-\theta)\left[\alpha_{1} L+\left(1-\alpha_{1}\right)\right) \bar{X}\right]+\theta[(1-F(L)) E(X \mid X \geq L)+F(L) L] \geq L .
$$

It is easily checked that $(24)$ and (25) are equivalent. Thus, $\widehat{\alpha}_{1}(\phi)=\alpha_{1}(\phi)$ implies $\widehat{\alpha}_{2}($ res,$\phi)=\alpha_{2}(\phi)$ as best response. We now show the converse. In the sequential game, when ill informed, bank 1 prefers res to liq if

$$
\left.(1-\theta)\left[\alpha_{2} L+\left(1-\alpha_{2}\right)\right) \bar{X}\right]+\theta \bar{Z} \geq L
$$

where $\alpha_{2}$ is short-hand for $\widehat{\alpha}_{2}(r e s, \phi)$. The condition is the same in the simultaneous game, but with $\alpha_{2}$ short-hand for $\alpha_{2}(\phi)$. It follows that $\widehat{\alpha}_{2}($ res, $\phi)=$ $\alpha_{2}(\phi)$ implies $\widehat{\alpha}_{1}(\phi)=\alpha_{1}(\phi)$, thereby concluding the proof. 


\section{Appendix 2}

To complete the analysis, we briefly explore the case where the firstmover advantage in liquidation is non negligible (we restrict the discussion to the simultaneous game). Recall that, if it is the only one to foreclose, a bank gets the payoff $L+\varepsilon$ while the other lender gets $L-\varepsilon$. Compared to the equilibrium where $\varepsilon$ is arbitrarily close to zero, a larger value has two effects. First, well informed banks will now inefficiently foreclose unless their information is sufficiently favorable. Secondly, ill informed banks foreclose more often. Both effects reinforce one another.

To see this, let $X_{\varepsilon}^{\prime}$ denote the equilibrium cutoff such that an informed bank reschedules when observing $X \geq X_{\varepsilon}^{\prime}$. From a social point of view, rescheduling should take place when $X>L$. However, with $\varepsilon$ greater than zero, an informed bank will now foreclose if $X$ is sufficiently close to $L$. One reason is the possibility of gaining the first-mover advantage should the other lender reschedule. Another is that rescheduling is now dangerous as the other lender might foreclose because he is ill informed. The payoff then would be $L-\varepsilon$ rather than $L$ as in section 3 . At the same time, an ill informed bank will anticipate that the other lender, if informed, will be less prone to rescheduling. The strategy of an ill informed bank will therefore also change and lean more towards foreclosure. At the extreme, if $\varepsilon$ is large enough, the advantage from foreclosing is so large that it becomes a dominant strategy, whatever the signal received.

Otherwise, when the value of $\varepsilon$ is not too large, equilibrium strategies are similar to those already studied, except for the inefficient liquidation when at least one bank is well informed and the fact that inefficient rescheduling takes place less often when both banks are ill informed. In other words, the first-mover advantage in foreclosing remedies some of the excess rescheduling, but at the cost of excessive liquidations.

The frequency of inefficient foreclosing increases with $X_{\varepsilon}^{\prime}$. Let $\alpha_{\varepsilon}(\phi)$ denote the probability of liquidation by an ill informed lender, as a function of $\varepsilon$. As shown at the end of this appendix, the threshold triggering rescheduling for a well informed bank is then

$$
X_{\varepsilon}^{\prime}=L+\frac{(1-\theta) \varepsilon}{1-\alpha_{\varepsilon}(\phi)(1-\theta)} .
$$


As in section 3, an ill informed bank always reschedules if the probability of the other bank being well informed is sufficiently large. Specifically, $\alpha_{\varepsilon}(\phi)$ equals zero if

$$
\theta \geq \widehat{\theta}_{\varepsilon} \equiv \frac{L+\varepsilon-\bar{X}}{\left[F\left(X_{\varepsilon}^{\prime}\right) L+\left(1-F\left(X_{\varepsilon}^{\prime}\right)\right) E\left(X \mid X \geq X_{\varepsilon}^{\prime}\right)-\bar{X}\right]},
$$

where $X_{\varepsilon}^{\prime}=L+(1-\theta) \varepsilon$. It is easily verified that $\widehat{\theta}_{\varepsilon}$ is increasing in $\varepsilon$. When $\theta<\widehat{\theta}_{\varepsilon}$ but assuming it is not too small, an ill informed bank randomizes, rescheduling with probability

$$
1-\alpha_{\varepsilon}(\phi)=\frac{\theta\left[E\left(X \mid X \geq X_{\varepsilon}^{\prime}\right)-L\right]\left(1-F\left(X_{\varepsilon}^{\prime}\right)\right)-\varepsilon}{(1-\theta)(L-\bar{X})} .
$$

It is easily shown that $\alpha_{\varepsilon}(\phi)$ is larger than the corresponding value in proposition 1 . Note also that (29) holds only if $\theta$ is not too small, otherwise the expression becomes negative. Therefore, if $\theta$ is sufficiently small, the equilibrium is in pure strategies with $\alpha_{\varepsilon}(\phi)=1$. This is a further contrast with the equilibrium derived in section 3 .

Proofs of the statements in Appendix 2: We first derive the formula for $X_{\varepsilon}^{\prime}$ in (27). We write $\alpha_{\varepsilon}=\alpha_{\varepsilon}(\phi)$ for short. If a well informed bank plays res after observing $X \geq X_{\varepsilon}^{\prime}$, its expected payoff is

$$
\theta X+(1-\theta)\left[\alpha_{\varepsilon}(L-\varepsilon)+\left(1-\alpha_{\varepsilon}\right) X\right]
$$

given that the other lender will also play res if informed. If the bank plays liq, the expected payoff is

$$
\left((1-\theta)\left(1-\alpha_{\varepsilon}\right)+\theta\right)(L+\varepsilon)+(1-\theta) \alpha_{\varepsilon} L
$$

For $X_{\varepsilon}^{\prime}$ to define a cutoff point, the two payoffs must be equal at $X=X_{\varepsilon}^{\prime}$, which leads to $(27)$.

To prove $(28)$, set $\alpha_{\varepsilon}=0$ in $(27)$ so that $X_{\varepsilon}^{\prime}=L+(1-\theta) \varepsilon$. If it plays res, an ill informed bank gets

$u\left(\right.$ res, $\left.\alpha_{\varepsilon} \mid \phi\right)=\theta\left\{\left(1-F\left(X_{\varepsilon}^{\prime}\right)\right) E\left(X \mid X \geq X_{\varepsilon}^{\prime}\right)+F\left(X_{\varepsilon}^{\prime}\right)(L-\varepsilon)\right\}+(1-\theta) \bar{X}$. 
If it plays $l i q$, the expected payoff is

$$
u\left(l i q, \alpha_{\varepsilon} \mid \phi\right)=\theta\left\{\left(1-F\left(X_{\varepsilon}^{\prime}\right)\right)(L+\varepsilon)+F\left(X_{\varepsilon}^{\prime}\right) L\right\}+(1-\theta)(L+\varepsilon) .
$$

One easily checks that $u($ res, $\alpha \mid \phi) \geq u($ liq, $\alpha \mid \phi)$ is equivalent to $\theta \geq \widehat{\theta}_{\varepsilon}$ as defined in (28). Note that $\widehat{\theta}_{\varepsilon}<1$ only if $\varepsilon$ is not too large, which is implicitly assumed here.

To prove (29), assume $\theta<\widehat{\theta}_{\varepsilon}$ and write $\pi$ for the belief that an ill informed bank assigns to the event that the other lender plays res. At equilibrium, $\pi=\theta\left(1-F\left(X_{\varepsilon}^{\prime}\right)\right)+(1-\theta)\left(1-\alpha_{\varepsilon}\right)$. For an ill informed bank, the payoff from liq is therefore

$$
\pi(L+\varepsilon)+(1-\pi) L
$$

The payoff from res is

$$
\pi\left(\frac{\theta\left(1-F\left(X_{\varepsilon}^{\prime}\right)\right)}{\pi} E\left(X \mid X \geq X_{\varepsilon}^{\prime}\right)+\frac{(1-\theta)\left(1-\alpha_{\beta}\right)}{\pi} \bar{X}\right)+(1-\pi)(L-\varepsilon) .
$$

Substituting for $\pi$ and setting the two payoffs equal to one another leads to (29). Note that the equality is consistent with $\alpha_{\varepsilon}(\phi)<1$ only if $\theta$ is not too small.

Finally, we prove that $\alpha_{\varepsilon}(\phi)>\alpha(\phi)$, where the latter is as defined in proposition 1. From (27) and (29), $X_{\varepsilon}^{\prime}=L$ and $\alpha_{\varepsilon}(\phi)=\alpha(\phi)$ when $\varepsilon=0$. Now, from $(29), \alpha_{\varepsilon}(\phi)$ is increasing in $\varepsilon$. It is also increasing in $X_{\varepsilon}^{\prime}$ since

$$
\frac{\partial \alpha_{\varepsilon}(\phi)}{\partial X_{\varepsilon}^{\prime}}=\frac{f\left(X_{\varepsilon}^{\prime}\right)\left(X_{\varepsilon}^{\prime}-L\right)}{(1-\theta)(L-\bar{X})}
$$

and $X_{\varepsilon}^{\prime}>L$ when $\varepsilon>0$. The two results together imply $\alpha_{\varepsilon}(\phi)>\alpha(\phi)$ as claimed. 


\section{References}

Banerjee A. (1992), "A simple model of herd behavior", Quarterly Journal of Economics 107, 797-817.

Blustein P., And the money kept rolling in (and out): Wall Street, the IMF, and the bankruptcy of Argentina. (New York, Public Affairs, 2005).

Bolton, P. and D. Scharfstein, "Optimal debt structure and the number of creditors", Journal of Political Economy 104(1), 1-25.

Brandenburger A. and B. Polak (1996), When managers cover their posteriors: making the decisions the market wants to see, Rand Journal of Economics, 27, 523-541.

Burkart, M. (1995), "Initial shareholding and overbidding in takeover contests", Journal of Finance 50(5), 1491-1515.

Degeorge, F. , J. Patel and R. Zeckhauser (1999), Earnings management to exceed thresholds, Journal of Business, 72, 1-33.

Degeorge, F. , J. Patel and R. Zeckhauser (2005), The market reactions to earnings thresholds, mimeo, University of Lugano.

De Meza, D. and D. C. Weiss (1987), "Too much investment: a problem of asymmetric information", Quarterly Journal of Economics, 281-292.

Detragiache, E. (1994), Public vs. private borrowing: A theory with implications for bankruptcy reform, Journal of Financial Intermediation, 3, 327-354.

Detragiache E. and P.G. Garella (1996), Debt restructuring with multiple creditors and the role of exchange offers, Journal of Financial Intermediation, 5, 305-336.

Detragiache, E., P.G. Garella and L. Guiso (2000), "Multiple versus single banking relationships: theory and evidence", Journal of Finance 55(3), 1133-61. 
Dewatripont, M. and E. Maskin (1995), "Credit and efficiency in centralized and decentralized economies", Review of Economic Studies 62, 541-555.

Engelbrecht-Wiggans, R., P. R. Milgrom and R. J. Weber (1983), "Competitive bidding and proprietary information", Journal of Mathematical Economics 11, 161-169.

Feddersen T.J, and W. Pesendorfer (1996), "The Swing Voter's Curse", American Economic Review, 86(3), 408-424.

Farrell, J. and M. Rabin (1996), "Cheap talk", Journal of Economic Perspectives $10(3), 103-118$.

Guiso, L. and R. Minetti (2004), "Multiple creditors and information rights: theory and evidence from US firms", CERP, WP no. 4278.

Hart, O. and J. Moore (1995), "Debt and seniority: An analysis of the role of hard claims in constraining management", American Economic Review, 85, 567-585.

Jappelli T. and M. Pagano (1993), "Information sharing in cedit markets", Journal of Finance, 48, 5, 1693-1718.

Kahl M. (2002), "Economic distress, financial distress and dynamic liquidation", Journal of Finance, 57, 1, 135-168.

La Porta R., F. Lopez-de-Silanes and A. Shleifer (2002), "Government ownership of banks", Journal of Finance, 57, 265-301.

La Porta R., F. Lopez-de-Silanes and G. Zamarripa (2003), "Related lending", Quarterly Journal of Economics, 118, 1, 231-268.

Mitchell, J. (2001), Bad Debts and the Cleaning of Banks' Balance Sheets: An Application to Transition Economies, Journal of Financial Intermediation 10, 1-27.

Myerson, R. and M. Satterthwaite (1983), "Efficient mechanisms for bilateral trading", Journal of Economic Theory 28, 265-281. 
Ongena S. and D.C. Smith (2000), What determines the number of bank relationships? Cross-country evidence, Journal of Financial Intermediation, 9, 26-56.

Padilla G. and M. Pagano (2000), "Sharing default information as a borrower's discipline device", European Economic Review, 1951-1980.

Perotti, Enrico C. (1993), Bank Lending in Transition Economies, Journal of Banking and Finance 17, 5: 1021-1032.

Petersen, M. A. and R. Rajan (1994), "The benefits from lending relationships: evidence from small business data", Journal of Finance 49, 3-37.

Rajan, R. (1992), "Insiders and outsiders: The choice between informed and arm's-length debt", Journal of Finance, 47, 4, 1367-1400.

Rajan, R. (1994), "Why credit policies fluctuate: A theory and some evidence", Quarterly Journal of Economics, 109, 2, 399-441.

Thakor, A. (2005), "Do loan commitments cause overlending?", Journal of Money, Credit and Banking, 37, 6, 1067-1099. 